\title{
Potencialidades pedagógicas dos movimentos sociais populares
}

Rosalvo Schütz ${ }^{1}$

No presente trabalho, evidenciaremos o potencial de dimensões pedagógicas inerentes à dinâmica atual dos movimentos sociais populares. A partir deles, enquanto espaços concretos de questionamento, ruptura e projeção social, procuraremos vislumbrar perspectivas emancipatórias.

A inevitável situação de confrontação externa e de vivenciamentos radicais internos exigem dos movimentos sociais populares uma postura de constante enfrentamento da totalidade social, que vai do cotidiano ao estrutural. Muito além de classificar o potencial dos mesmos a partir de parâmetros idealistas, trata-se de tomar as condições e pressupostos existentes, com suas contradições, fraquezas e potencialidades, e as transformar em material de uma utopia concreta e vivenciável.

${ }^{1}$ Doutorando em Filosofia na Universidade de Kassel, Alemanha.

Civitas, Porto Alegre, v. 4, nº 1, jan.-jun. 2004 


\section{Pressupostos}

Ao buscar colocar em evidência as potencialidades pedagógicas dos movimentos, estamos partido de três pressupostos que queremos explicitar desde logo, e que dizem respeito a uma definição dos movimentos sociais populares, à primazia pedagógica do processo e aos mecanismos de legitimação.

\section{Movimentos sociais populares}

Os movimentos sociais populares, para nós, caracterizam-se pelo seu caráter coletivo e dinâmico, socialmente organizado e que, de forma consciente e coletiva, buscam transformar situações de opressão, sejam elas econômicas, políticas, sociais, culturais, raciais, de gênero ou de opção sexual. Diferenciamse, portanto, daqueles movimentos que não buscam de forma alguma rupturas sociais, e dos atores sociais que são regrados pela legalidade institucional do direito moderno ou subordinados a organizações institucionais como partidos, ONGs ou pastorais. É sempre a postura prática que define o caráter popular ou não-popular de um movimento. Assim, por exemplo, uma parte do movimento sindical, que ousa estender sua ação para além do papel que lhe é institucionalmente delegado, pode ser considerado parte dos movimentos sociais populares. Esta concepção viabiliza, portanto, a construção de uma identidade de classe a partir da diversidade.

Enquanto expressão visível e viva de um conflito social e não apenas enquanto sinais de crise, os movimentos estão em constante transformação. Transformações estas que se pautam pelas relações sociais tensas em que estão inseridos e/ou que vivenciam internamente. A identificação de causas e atores conflitivos bem como o alcance da projeção do novo, no entanto, dependem muito da capacidade de análise e reflexão sobre esta realidade complexa. Os movimentos sociais populares são, pois, por si só, a unidade entre teoria e prática, sujeito e objeto. É no processo mesmo, enquanto espaço de construção constante, consciente e coletiva, que se vão estabelecendo as condições de ruptura individual e social. Meios e fins se condicionam mutuamente e, por isso, desaparecem enquanto atos distintos na práxis cotidiana. Obviamente estas não são questões totalmente conscientes e incorporadas no cotidiano. A existência e definição de um movimento social popular é antes um constante processo de libertação das condições sociais opressoras que se manifestam também no vanguardismo e no espontaneísmo internos. O progressivo tornar-se consciente (da consciência em si para a consciência para si) desta condição e de seus potenciais, no entanto, é determinante para poder avançar em direção a rupturas estruturais. 


\section{Primazia pedagógica do processo}

Nossas leituras da realidade bem como os nossos projetos de futuro se orientam dentro de um horizonte compreensivo por nós construído a partir dos contextos em que vivemos. Dependendo deste, espande-se ou limita-se nossa capacidade de pensar e agir para além do que nos é apresentado como normal e necessário. É um movimento circular no qual interagem simultaneamente nossa leitura da realidade presente, da história e a construção de nossos sonhos e utopias. É a possibilidade que temos de nos libertar de qualquer pretenso determinismo histórico ou social. Todos nós vivemos, de uma ou outra forma, orientados por essas utopias. Conseguir fortalecer utopias, e portanto leituras e vivências da realidade, orientados pela esperança e construção de um sentido de vida que ultrapasse os supostos determinismos da dinâmica atual é um dos principias desafios enfrentados pelos movimentos sociais populares. Denunciar a crueldade, mas também, a partir dela mesma, apontar para possíveis desejáveis, são momentos decisivos para levar ao engajamento e gerar esforços pessoais e coletivos.

A unidade entre a realidade e o possível, entre teoria e prática, é a organização e a vida concreta dos movimentos. É, pois, na construção dos instrumentos, das metodologias, formas de relação e ação que vai se constituindo, enquanto processo, o inédito. Pois é ali que se constitui o capital cultural/social, nossas estruturas de sentimentos e, portanto, de conduta em relação aos outros, aos meios e conosco mesmos. São dimensões não simplesmente ensináveis por teorias, mas que também não emergem espontaneamente a partir da realidade reificada. O envolvimento da integridade emotiva das pessoas e a reflexão crítica e criativa são ingredientes indispensáveis. As conquistas e mudanças, por poderem ser consideradas frutos da construção ou da conquista coletiva e consciente, adquirem, assim, um sentido emancipatório.

\section{Mecanismo de legitimação}

A ideologia dominante procura apresentar os movimentos sociais populares como sendo expressão de "doenças sociais", interesses corporativistas ou, no máximo, como expressões de "falhas" no sistema social. Intenciona com isso evitar que a dinâmica no seu todo seja questionada. Pressupõe-se que essa dinâmica, bem como o papel do indivíduo que lhes é inerente, sejam de naturalidade necessária.

Na concepção de mundo que se hegemonizou na modernidade, o indivíduo é concebido como formalmente livre em sua vontade, sem que, no entanto, haja uma preocupação coletiva com a realidade material deste, como era o caso nas 
organizações sociais anteriores. Assim, por exemplo, todos podemos livremente vender ou comprar a força de trabalho, sem que nenhum um rei, clérigo ou senhor de escravos tenha o direito de obrigar-nos a fazê-lo. As relações de exploração e opressão tornaram-se muito mais sutis. Pela primeira vez na história da humanidade, o conjunto da sociedade passou a não se sentir responsável pela miséria de seus integrantes. A culpa passa a ser do indivíduo. Economia e política passam a estar formalmente separados. Delimitando a liberdade à esfera da política, ela pôde ser formalmente universalizada, já a base econômica passou a ser tida como resultado de "leis naturais". E a "sociedade tem que ser modelada de maneira tal a permitir que o sistema funcione de acordo com as suas próprias leis" (Polanyi, 2000, p. 77). A conseqüência radical desta visão de mundo é que todas situações materiais, da opulência à miserabilidade extremas, são delegadas à responsabilidade dos indivíduo atomizados. A violência estrutural inerente a esta dinâmica, na qual economia e política são dimensões complementares, fica, assim, intocável.

Superar essa concepção e seus pressupostos significa, portanto, romper com a concepção de sociedade na sua totalidade, que engloba tanto a esfera econômica como a política e se funda na concepção de individuo que lhe é inerente. Enquanto espaços coletivos de invenção de inéditos possíveis na história, os movimentos sociais populares são um espaço privilegiado para tal.

\section{Níveis formativo-pedagógicos nos movimentos sociais populares}

A capacidade de inovar sempre, de se adaptar, de agir reflexiva e teleologicamente, são inerentes a todo ser humano e a todos os grupos e sociedades humanas. Incorporar essa concepção e conseqüente postura epistemológica, implica conceber o conhecimento e a transformação como sendo construção social ativa. Implica superar a idéia de transferência de conhecimento ou de "conscientização" em vista de verdades preestabelecidas. No engajamento concreto em espaços sociais e históricos, explicitando contradições e num permanente processo de reflexão-acão permeado pelo diálogo coletivo, realiza-se a simultânea denúncia das situações injustas e o anúncio das novas possibilidades. Nem o determinismo do presente nem a predeterminação do futuro cabem nessa concepção. Neste sentido buscaremos identificar três níveis da realidade nos quais aparecem desafios e oportunidades específicas para os movimentos sociais populares. A explicitação desses níveis fará com que possam ser melhor enfrentadas suas especificidades enquanto momentos pedagógicos complementares, otimizando oportunidades e acúmulos já existentes.

Novas identidades pessoais 
O fato de a própria estrutura e objetivos dos movimentos sociais populares serem organizados em vista da superação do status quo atual e seus pressupostos, faz dos mesmos um locus privilegiado da construção de novos referenciais para os seus integrantes. Neles as individualidades podem tornar-se conscientes dos mecanismos ideológicos que pesam sobre eles e o quanto a sua visão de mundo e ação está impregnada por estes. Na maior parte das vezes, é a situação existencial integral dos indivíduos que é posta em questão, oportunizando um processo de aprendizagem que ultrapassa os limites da racionalidade moderna. E, se é verdade que as "premissas fundamentais de todo sistema racional são não-racionais, são noções, relações, distinções, elementos, verdades, (...) que aceitamos apriori porque nos agradam" (Maturana, 2002, p. 52), então este nível de ação é fundamental para a consolidação e vigorosidade estratégica dos movimentos sociais populares.

O núcleo temático desse nível é a resistência e a superação das determinações da totalidade social capitalista nas microrrelações cotidianas. Pois é nestas, através de meios cada vez mais sofisticados como a comunicação de massa e uma outra infinidade de meios semióticos, sociológicos e psicológicos que interferem sobremaneira nas estruturas de sentimentos e no direcionamento e manejo dos sonhos e utopias pessoais, que o sistema se está legitimando, ao influenciar níveis cada vez mais implícitos e inconscientes. Estes métodos atingem cada vez mais a integralidade das pessoas, tornando-as mais dependentes e modeladas aos padrões de consumo e produção apropriados à reprodução da estrutura existente. Resulta daí o reforço da idéia de indivíduo que, por meios competitivos, busca a felicidade na aquisição de produtos carregados simbolicamente pelas propagandas. Mesmo que não se tenha acesso a estes padrões de consumo, os espetáculos de imagens e identificação com personalidades mistificadas criam a ilusão de co-participação nesses padrões idealizados e projetados. Assim, mantém-se ativado o desejo mimético determinador da conduta individual e coletiva. Torna-se difícil, para os indivíduos imersos nesta realidade fetichizada, perceber alternativas que ultrapassem os limites do esforço individual. Problemas de ordem coletiva aparecem como resultados de atos imorais dos indivíduos, ou determinações naturais inevitáveis. Mudanças sociais fundadas na ação coletiva são, assim, inviabilizadas. Resulta daí uma subjetividade que se sente extremamente impotente ante as determinações estruturais e que canaliza e delimita as suas potencialidades e criatividades aos limites do egoísmo pessoal e estruturas sociais correspondentes.

Por ser um espaço de redefinição do imaginário, do sentido da vida e das utopias individuais, os movimentos sociais populares contribuem para o questionamento e superação destes limites e na liberação de novas formas de sensibilidade e relação. Esta mudança, porém, está condicionada pelas 
oportunidades de experienciar possibilidades reais de transformação, viabilizadas pela vivência no movimento. Sentir que há a possibilidade de mudança no entorno é ponto de partida para engajamentos maiores. Pessoas protagonistas dos movimentos sociais populares geralmente identificam o seu engajamento neste tipo de vivências. Obviamente elas não conduzem automaticamente ao engajamento, mas sem as vivências o engajamento não existe. Assim, as "necessidades sociais podem tonar-se objeto de desejos coletivos, coesionados a partir de experiências de esperança no cotidiano das pessoas. Sem este suporte experiencial, geralmente sobram apenas propostas centralistas, amparadas em algum mito do Estado ideal, ou ilusões ideológicas sem nexo com o cotidiano das pessoas." (Assmann e Mo Sung, 2000, p. 28).

Possibilitar experiências de pertencimento, de pluralidade e de transformações vivenciáveis, como sendo uma espécie de conversão de valores, é de importância vital para a consolidação e renovação do movimento. Mas elas adquirem sentido emancipador, tornam-se força social, na medida em que são constante e criticamente refletidas. O tornar-se consciente da experiência vivida é que supera o voluntarismo disperso e vulnerável. Por isso, momentos de reflexão, formação, avaliação e planejamento da própria ação tomam sentido estratégico tanto para os indivíduos como para os movimentos. Há, no entanto, o outro extremo deste aspecto, no qual ocorre uma espécie de passagem forçada para perspectivas mais amplas de transformação, para níveis estratégicos que exigem uma dedicação e acúmulos teórico quantitativos muito grandes, o que muitas pessoas não estão dispostas, e nem podem, realizar. Isso muitas vezes tem levado a uma "politização” forçada das questões. Há por trás disso, uma crença equivocada de que todas as pessoas deveriam chegar a ter esses acúmulos, e de que estes são adquiríveis sem um processo de vivenciamentos ativos e concretos. Quando, muito antes de ser uma questão teórica é uma questão de postura, de ponto de vista, de método, que está em jogo. Por caírem nesta armadilha epistemológica, muitos movimentos e lideranças acabaram por se afastar da realidade vivencial da população e realizando uma violência contra o potencial de energias humanas disponíveis, enfraquecendo ou perdendo as perspectivas emancipadoras.

Ao observarmos, como sujeitos externos, a dinâmica interna dos movimentos sociais populares, ou mesmo suas manifestações massivas, com regras razoavelmente estabelecidas e objetivos razoavelmente claros, podemos ser levados a afirmar, que existe ali um sujeito coletivo, quase que um "objeto empírico unitário" (Melucci, 2001, p. 25), que se sustenta por si só. No entanto, um movimento só se sustenta por ter uma base social fora dos seus limites, onde é gestado e legitimado. Seu surgimento só é possível por existirem, antes disso, redes de relações, constituídas nos subterrâneos da oficialidade e do imaginário social que, quando coesionados, podem tornar-se 
visíveis e conscientes. É um referencial ético-moral comum, que possibilita uma identidade nos e com os movimentos sociais populares, sem a qual o movimento não seria possível, pois não possuiria bases estruturadoras e porque não seria reconhecido socialmente. A existência de pessoas que compartilhem sentidos, com vivências de esperança comuns com um "desejo de convivência num projeto comum de vida" (Melucci, 2001, p. 77), é fundamental para a estruturação e legitimação social do movimento. Mesmo que as dimensões instrumentais e estratégicas não estejam claras para todos, define-se aí uma postura marcadamente diferente daquela instigada pela normalidade social.

Por isso, a formação de novas subjetividades individuais, seja no movimento ou em outros espaços sociais, tem importância estratégica para os movimentos sociais populares. Eles próprios são o locus privilegiado para tal. Movimentos que não trabalham para fortalecer e diversificar esta dimensão estão fadados ao enfraquecimento e posterior desaparecimento ou a verem suas demandas serem diluídas na burocratização conivente com o existente.

\section{Explicitação das estruturas de poder e fundamentação de novas práticas}

Não só para os indivíduos, mas também para toda a sociedade, os movimentos sociais populares podem, no seu processo de gestação, constituição e intervenção, ter um caráter pedagógico, porquanto suas mobilizações e reivindicações tornam visíveis debilidades do sistema e forçam o poder a tomar posições e, neste sentido, são também uma forma de explicitação das estruturas de poder. De forma que a "ação coletiva nas sociedades complexas impede que o sistema se feche, produz inovação e intercâmbio das elites, faz entrar na área do decidível aquilo que está excluído, denuncia as zonas de sombra e de silêncio que a complexidade cria" (Melucci, 2001, p. 134). Além disso, enquanto organizações coletivas não determinadas pela legalidade vigente e com intencionalidade e ações críticas em relação ao existente, apontam e introduzem novos valores, culturas e horizontes na dinâmica social, através do seu capital social e político.

Os momentos da luta cotidiana, ${ }^{2}$ que dizem respeito a uma melhor distribuição de bens no inteiror do sistema organizativo, a ampliação das possibilidades de decisão e da participação nestes, bem como as ações voltadas para melhorar a posição nos processos decisórios, constituem o núcleo

\footnotetext{
2،A luta cotidiana pelas reformas, pela melhoria da situação do povo trabalhador no próprio quadro do regime existente, pelas instituições democráticas, constitui, mesmo para a social-democracia, o único meio de travar a luta de classe proletária e trabalhar no sentido da sua finalidade, isto é, a luta pela conquista do poder político e supressão do assalariado.” (Luxemburgo, 1999, p. 17)
} 
temático deste nível de ação. A ação social cotidiana é onde são tomadas, vivenciadas e possivelmente superadas, as contradições. Material básico sem o qual os movimentos sociais populares correm o risco de se perderem em profetismos abstratos ou basismos sem consequiências. É o espaço de efetivação organizativa que gera um tensionamento político-social viabilizando conquistas e reformas significativas para a vida de muitas populações, ainda que não alterem diretamente as estruturas de reprodução da sociedade. A existência dos direitos conquistados, contudo, depende fundamentalmente da capacidade de constante mobilização, organização e proposição da organização popular. O sistema, apesar de poder conviver com eles, haverá de suprimi-los, caso não haja mais resistência da base que os defende, ou seja, caso julgue desnecessário lançar mão destes artifícios para garantir seu reconhecimento.

A relação entre capital e trabalho, expressa nas negociações entre sindicatos de trabalhadores e empresários, enquanto espaços legalmente constituídos e juridificados, também pertencem a este nível de ação. Pois se sabe que melhorias salariais, por si só, não significam nenhuma ruptura com o sistema. Muitas vezes, inclusive, é preciso que o sistema vá bem, para que haja salários razoáveis. Os trabalhadores sabem que, no caso de crises, eles são os primeiros a ser sacrificados, tanto com diminuição de salários como com perda dos postos de trabalho. Isso, no entanto, não diminui a importância destas organizações enquanto espaços de explicitação das relações de poder, geração de novos valores e no garantir de direitos perante o capital.

Também as reivindicações de muitos movimentos sociais populares, como a obtenção de moradias, de terra, de trabalho, igualdade de direitos políticos etc., vistos isoladamente, não contradizem o sistema atual em sua essência. Mas da capacidade de mobilização desses movimentos depende a obtenção ou não dos direitos correspondentes. As estratégias de conquista desses direitos materiais podem ser diversas, como greves, ocupação de espaços institucionais, mobilizações sociais e culturais, ou mesmo atos de desobediência civil. Todas as formas, no entanto, baseiam-se fundamentalmente em argumentos/elementos externos ao sistema, como o bem-estar material e a qualidade das relações etc., elementos estes não submetidos à racionalidade do sistema. $\mathrm{O}$ que torna os movimentos sociais populares uma espécie de laboratório de construção de outros princípios de vida que podem servir de base para transformações mais profundas. Sem o consciente trabalhar dessa dimensão, presente enquanto potencial em todas as formas de ação dos movimentos sociais populares, as conquistas ficam, quando muito, no nível da legalidade e dos acordos. Mesmo um governo de transformação, por mais sincero que seja em suas intenções, sem esta base de pressão, renovação e crítica, não pode efetivar mudanças significativas, nem mesmo as possíveis dentro do sistema vigente, muito menos contribuir para a superação desse sistema. 
Ao obrigar as estruturas com finalidades conservadoras a se reestruturarem, os movimentos sociais populares insidem de forma indireta sobre a sociedade, que não aquela que diz respeito às suas bandeiras. Instigada pelas ações dos movimentos, a sociedade é estimulada a se posicionar a respeito de temas conflituosos, gerando, assim, um aumento no nível de politização e criticidade na população, trazendo para a cena pública questões e enfoques antes ausentes. Instaura-se, desta forma, uma processualidade pedagógica que não se restringe às áreas de atuação direta dos movimentos sociais populares.

Ao evidenciar papéis que vão além de seus objetivos imediatos, amplia-se a visualização do processo histórico de transformação, dificultando a absolutização, sectarização e os sentimentos de fracasso em torno de questões pontuais. Pode, por exemplo, um movimento social popular não atingir seus objetivos diretos e contribuir tanto ou mais para um processo de transformação do que um movimento que conquiste imediatamente seus objetivos. Por não conseguirem fazer desses momentos oportunidades de fortalecimento da identidade crítica e da projeção da ação para além dos objetivos específicos, muitos movimentos não superam seu caráter meramente reivindicativo.

Nesse nível de ação ocorrem acúmulos coletivos que podem até mesmo servir para outras organizações sociais. Também capitais de outras organizações podem ser incorporadas e potencializadas. Vistos dessa forma, os movimentos sociais populares são os canais através dos quais dimensões, grupos e questões reprimidas pelo sistema vêm à tona, tornam-se tematizáveis, subsidiando processos sociais de transformação.

Alicerçadas nos acúmulos coletivos adquiridos nas lutas específicas, constroem-se as possibilidades de identificação com outros movimentos, seja por causa das bandeiras, seja por causa dos pressupostos e posturas comuns. A luta contra a opressão, exploração e desigualdades geralmente é o mote articulador. Assim, visualizar-se um horizonte de transformação que vai além das bandeiras imediatas, que no entanto, sem o constante relacionar-se com as mesmas, não seria possível.

\section{Refundação do Político}

Com muita freqüência, setores e propostas oriundas dos movimentos sociais populares têm conseguido ocupar espaços governamentais ou estatais consideráveis. Estas situações têm criado oportunidades de intervenção direta em políticas e na efetivação de objetivos dos movimentos sociais populares. Por outro lado, esses setores vêem-se também obrigados a aceitar as regras institucionais legais inerentes ao estado liberal de direito e zelar pela sua manutenção. Isso tem causado crises, tanto nos indivíduos de origem popular 
como nos movimentos que, através de seus quadros, ocupam estes espaços. $\mathrm{Na}$ origem dessas crises está, essencialmente, a disparidade entre os impulsos originais e os limites efetivos impostos pela racionalidade inerente ao estado moderno.

A não-efetivação de bandeiras históricas dos movimentos por parte dos governos populares é, muitas vezes, atribuída à má vontade política dos indivíduos que ocupam os cargos nos governos. O que em alguns casos pode ser verdade. A questão essencial, no entanto, diz respeito aos limites e possibilidades da própria institucionalidade ocupada. Entender esta dinâmica é questão fundamental numa estratégia de transformação social ampla, a fim de clarear os limites, potenciais e possíveis armadilhas da ocupação de espaços de governo. Ao entendê-la, seremos certamente remetidos a pôr em questão e repensar a própria forma como se organiza o Político na atualidade.

$\mathrm{Na}$ atual estrutura política há uma íntima relação complementar com o modo de produção capitalista. Ambos integram a mesma totalidade e se condicionam mutuamente. Os direitos são direitos individuais e, por mais diferenciados que possam ser, jamais podem ultrapassar este limite, característico do estado de direito. $\mathrm{O}$ bem-estar e a reprodução material são atribuídos à responsabilidade dos indivíduos, restringindo-se o estado, a rigor, a garantir a liberdade individual e o direito à propriedade de seus membros. ${ }^{3}$ Daí que as possibilidades de ação no interior da estrutura estatal encontram-se limitadas por regras e regidas por uma lógica, de forma que a manutenção e reprodução da totalidade social seja garantida. Para poder garantir isso abandonou-se uma preocupação presente em todas formas de organização social anteriores, qual seja, decidir e incidir sobre a melhor maneira de produzir, trocar, consumir e de garantir a existência e sobrevivência dos seus membros. A configuração do espaço político como o conhecemos hoje, portanto, é a forma como foi estruturado o Político na nossa época, baseado em um modo de produção alicerçado sobre a exploração do trabalho (Lukács, 1978, p. 119ss).

Dessa forma, a ação política está limitada pela formalidade das leis, pela formalidade do direito. A legalidade dos procedimentos sobrepõe-se à legitimidade. Nenhuma aspiração popular pode mais ser efetivada pelo estado, sem que este cumpra os requisitos formais que o direito impõe. Esses limites impedem fundamentalmente que haja qualquer interferência na lógica da reprodução material da sociedade, fundada na exploração do trabalho e na

\footnotetext{
3 "Nesse mecanismo trata-se de inclusão jurídico-legal das pessoas no todo da comunidade, enquanto no interior desta verifica-se uma crescente desigualdade material, que causa a exclusão de camadas inteiras do gozo da riqueza produzida socialmente." (Flickinger, 2003, p. 167)
} 
propriedade privada. Mesmo o sistema representativo moderno tem esta função conservadora, na medida em que exclui o povo das decisões políticas importantes, que passam a ser aceitas como democráticas, ainda que não passem de negociações de interesses parciais, no parlamento. $\mathrm{O}$ próprio conceito de cidadania, pode ser, assim, um instrumento de dominação e neutralização, na medida em que seu significado se reduz aos limites da institucionalidade estatal burguesa, inviabilizando a tematização de temáticas com potenciais emancipatórios que ultrapassam a racionalidade do Direito moderno.

Conquanto existam muitas fendas no interior da organização política atual, onde os movimentos sociais podem interferir com conquistas substantivas, e ainda que a participação nesses espaços seja fundamental para o desvelamento de sua dinâmica e para a colocação de novos desafios, as principais bandeiras, ou seja, aquelas que propõem uma nova forma de sociabilidade, de relações de poder, de produção etc., não são tematizáveis e muito menos efetiváveis dentro dos limites dos atuais mecanismos da estrutura estatal. Conscientes disso os movimentos sociais populares jamais deixarão suas utopias e ações se aprisionarem pelos trilhos da institucionalidade. Esta constatação, no entanto, só é possível na medida em que elementos não regidos pela racionalidade instrumental do estado e da economia entram em cena. A origem desses elementos remete a valores oriundos dos movimentos sociais populares.

Cientes disso, as forças oriundas dos movimentos sociais populares terão certamente uma postura diferenciada na sua ação e relação nos e com os espaços institucionais. Muitas vezes, por não haver esta compreensão, há um empenho muito mais forte no revigoramento de estruturas institucionais, notadamente as estatais, que, a rigor, têm funções conservadoras, do que na construção e fortalecimento de instrumentos de poder popular. A autonomia da organização popular, em vez de ser estimulada é, nestes casos, atrelada a estruturas estatais. Até mesmo pessoas e movimentos com sinceras intenções de transformações caem nesta armadilha.

A passagem de uma postura essencialmente reivindicatória para uma postura mais propositiva nem sempre veio acompanhada de uma superação da visão paternalista de stado. Este continuou sendo encarado como sendo o local, por excelência, o "carro chefe", do fazer político e, portanto, da transformação. Sendo que não se elaborou uma crítica correspondente à sua lógica e estrutura. Aos poucos, o processo de confronto e aprendizagem com as estruturas estatais vem rompendo com a idéia de que todos os problemas econômico-sociais podem ser resolvidos sem que se altere a estruturação básica do espaço do Político atual. Clarear criticamente os potenciais e limites da ocupação de espaços institucionais é um processo de aprendizagem que recém está em seu 
início para os movimentos sociais populares. Possibilitado pelas ricas experiências, mesmo que contraditórias, que estão ocorrendo tanto em níveis locais como nacionais, a questão está tornando-se cada vez mais presente. $\mathrm{O}$ que já se está delineando com claridade é que não bastam as leis e os caminhos legais, mesmo que num governo popular, mas que novas formas de constituir o espaço do Político precisam ser inventadas. A constante organização e mobilização popular enquanto referência não determinada pela racionalidade oficial é vital para que isso aconteça.

\section{Perspectivas}

Evidenciando diferentes níveis pedagógicos dos movimentos sociais populares, procuramos desvendar funções estratégicas dos mesmos. Algo mais do que as bandeiras imediatas e cotidianas pode surgir e se desenvolver no modo como os movimentos sociais populares se constituem internamente e na forma como interagem com o conjunto da sociedade. Estas dimensões, trabalhadas de forma consciente, podem ativar enormes potencialidades objetivamente já existentes.

Isso, todavia, requer uma postura que implica em construir horizontes e princípios que progressivamente vão instaurando novos ordenamentos sociais a partir das lutas e práticas cotidianas e do confronto com as estruturas existentes, num processo de permanente aprendizagem. Implica ir para além da simples junção de indivíduos para conquistar, pela soma das forças individuais, objetivos e/ou direitos que individualmente não se conseguiria. Embora este possa ser seu ponto de partida, e o confronto com estruturas e lutas cotidianas seja o "combustível" cotidiano dos movimentos sociais populares, na processualidade do seu modo de ser é que se constitui seu sentido mais profundo, as condições de possibilidade de seu caráter revolucionário. A fundamentação de uma nova ordem social só pode emergir, ser aprendida, da própria organização popular embasada em impulsos não regidos pela racionalidade oficial, por isso ela é um permanente processo de aprendizagem.

Dar-se conta da radicalidade histórica e da sua importância pedagógica é fundamental para que as ações cotidianas dos movimentos sejam emprenhadas de sentidos transformadores. Foi esta postura diante da realidade que tornou os movimentos sociais populares, no Brasil, tão significativos e que permitiu o desenvolvimento de uma grande diversidade de temas, metodologias, ações etc., com possilibidades pedagógicas fantásticas. A afirmação e aprofundamento dessa postura podem contribuir decisivamente para sugerir novas pistas de ações.

Não havendo caminho preestabelecido, a construção dos caminhos e o 
aprender constante com o próprio processo de construção destes, é que passam a ser o balizador da ação. As transformações repentinas dão lugar a processos de transformação. Também o estado não pode mais ser visualizado como sendo o lugar último a partir de onde, quando se estaria no poder, seria possível superar todas as mazelas e alcançar todas as utopias, embora o Político jamais deixe de ser o horizonte central das ações. Aspirações essenciais dos movimentos sociais populares simplesmente não podem ser efetivadas dentro dos limites da estruturação do Político na atualidade. Ou seja, a tomada do poder passa a ser encarada apenas como um momento dentro de uma dinâmica mais ampla, por mais decisivo que seja esse momento. $\mathrm{O}$ que não quer dizer que as questões políticas não continuem sendo centrais, mas elas não se deixam mais limitar pela estruturas e regras do estado moderno. Neste sentido a construção de outras formas de decisão e estruturação política passam a tomar importância crescente para os movimentos.

Tomar o indivíduo concreto e integral como referência parece garantir que os movimentos sociais populares não se percam em pautas que contemplam apenas um ou outro nível de transformação. Descortina-se, assim, toda uma trama de relações sociais, afetivas, simbólicas, econômicas etc. que pesam sobre os indivíduos e que simultaneamente fundamentam e legitimam as macroestruturas existentes. Permitem, assim, visualizar, com relativa simplicidade, a íntima relação dos modos de vida cotidianos com as macroestruturas sociais e econômicas.

De forma conseqüente, as atividades cotidianas dos movimentos sociais populares revelam as funções estratégicas de seu caráter pedagógico. É a partir de onde se estabelecem os alicerces para transformações estruturais mais profundas, sem que percam importância o engajamento crítico, a ampliação e transformação de espaços e instância existentes. São, além de formas de garantir e ampliar direitos no interior dos sistemas, oportunidades de aprendizado e formulação. Neste processo de imersão na realidade, evidenciando as suas contradições e simultaneamente, formulando formas de superação destes limites, é que se constitui, ou não, o caráter revolucionário do movimento. Por isso, ele é um processo que acontece intimamente relacionado com uma realidade, a partir da qual se constituem suas referências concretas. É uma tarefa fundamentalmente de construção coletiva, que se fundamenta nas carências imediatas das pessoas, passa pela explicitação dos mecanismos e estruturas de poder e, por fim, constitui novas formas e espaços de decisão e estruturação política.

O desafio colocado para os movimentos sociais populares é o de se organizarem de tal forma que, a um só tempo, estejam presentes os três níveis de ação e aprendizado destacados, a dizer, a construção cotidiana de novas 
subjetividades e modos de vida; ocupação, confronto e explicitação das contradições e limites das estruturas de poder existentes e a construção de novas formas de organização do espaço do Político. Orientados por este tripé pedagógico, viabiliza-se uma processualidade capaz de contemplar os impulsos inerentes aos movimentos, que não se coaduna com a racionalidade hegemônica, ou seja: seus potenciais emancipatórios. Obviamente, com a existência da diversidade de movimentos, e dentro de estratégias conjuntas, estes podem privilegiar mais uma ou outra esfera, num processo de complementaridade e solidariedade mútua, entre si e com outros atores.

\section{Referências}

ASSMANN, Hugo e MO SUNG, Jung. Competência e sensibilidade solidária: educar para a esperança. Petrópolis: Vozes, 2000.

CAMP. Movimentos sociais e estado: limites e possibilidades. Caderno de Debates, Porto Alegre, v. 2. 2001.

CARBONARI, Paulo César (Org.). Estado e sociedade civil no Rio Grande do Sul: debates dos sujeitos sociais populares (Resultado do debate dos Parceiros da Misereor, no RS, coordenado pelo CAMP, Cáritas-RS e CEAP). Passo Fundo, 2002.

FLICKINGER, Hans-Georg. Em nome da liberdade: elementos da crítica ao liberalismo contemporâneo. Coleção Filosofia 153. Porto Alegre: Edipucrs, 2003.

FREIRE, Paulo. Pedagogia do oprimido. 34ª ed. São Paulo: Paz e Terra, 2002.

GOHN, Maria da Glória. Teoria dos movimentos sociais: paradigmas clássicos e contemporâneos. $2^{\mathrm{a}}$. ed. São Paulo: Loyola, 2000.

LUKÁCS, Georg. Geschichte und Klassenbewustsein. Hermann Luchterhand Verlag: Darmstadt und Neuwied, 1978.

LUXEMBURGO, Rosa. Reforma ou revolução. São Paulo: Expressão Popular, 1999.

MANCE, Euclídes. Movimento popular e a revolução molecular. Disponível em: http:/www.rbc.org.br/redes.htm. Acesso em14 fev. 2003.

MARX, Karl. Manuscritos econômico-filosóficos. Lisboa: Edições 70, 1964.

MATURANA, Humberto. Emoções e linguagem na educação e na política. Belo Horizonte: Editora Ufmg, 2002.

MELUCCI, Alberto. A invenção do presente: movimentos sociais nas sociedades complexas. Petrópolis: Vozes, 2001.

PALUDO, Conceição. Educação popular em busca de alternativas: uma leitura desde o campo democrático e popular. Porto Alegre: Tomo Editorial, 2001.

POLANYI, Karl. A grande transformação: as origens da nossa época. Rio de Janeiro: Campus, 2000. 
PUTNAM, Robert D. Comunidade e democracia: a experiência da Itália moderna. Rio de Janeiro: Fundação Getúlio Vargas, 1996.

SCHÜTZ, Rosalvo. Religião e capitalismo: uma reflexão a partir de Feuerbach e Marx. Coleção Filosofia 126. Porto Alegre: Edipucrs, 2001.

SOBOTTKA, Emil. Movimentos sociais: a busca da ampliação do espaço político. In: FLICKINGER, Hans-Georg (Org.). Entre caridade, solidariedade e cidadania: história comparativa do Serviço Social Brasil-Alemanha. Porto Alegre: Edipucrs, 2000

VIEIRA, Luiz Vicente. A democracia em Rousseau: a recusa dos pressupostos liberais. Coleção Filosofia 52. Porto Alegre: Edipucrs, 1997.

Texto recebido em 14.12.03 e aprovado em 30.03.04 